\title{
Intervention to Enhance Communication About Newly Prescribed Medications
}

\author{
Derjung M. Tarn, $M D, P b D^{1}$ \\ Debora A. Paterniti, PhD ${ }^{2}$ \\ Deborab K. Orosz, BA \\ Cbi-Hong Tseng, $P b D^{4}$ \\ Neil S. Wenger, $M D, M P H^{4}$
}

'Department of Family Medicine, David Geffen School of Medicine, University of California-Los Angeles, Los Angeles, California

${ }^{2}$ Center for Healthcare Policy and Research and Department of Sociology, University of California-Davis Medical Center, Sacramento, California

${ }^{3}$ Harvard Medical School, Boston Massachusetts

${ }^{4}$ Division of General Internal Medicine and Health Services Research, David Geffen School of Medicine, University of California-Los Angeles, Los Angeles, California

Conflicts of interest: authors report none.

\section{CORRESPONDING AUTHOR}

Derjung Mimi Tarn, MD, PhD

David Geffen School of Medicine at UCLA

Department of Family Medicine

10880 Wilshire Blvd, Ste 1800

Los Angeles, CA 90024

dtarn@mednet.ucla.edu

\begin{abstract}
PURPOSE Physicians prescribing new medications often do not convey important medication-related information. This study tests an intervention to improve physician-patient communication about newly prescribed medications.

METHODS We conducted a controlled clinical trial of patients in 3 primary care practices, combining data from patient surveys with audio-recorded physicianpatient interactions. The intervention consisted of a 1-hour physician-targeted interactive educational session encouraging communication about 5 basic elements regarding a new prescription and a patient information handout listing the 5 basic elements. Main outcome measures were the Medication Communication Index (MCI), a 5-point index assessed by qualitative analysis of audio-recorded interactions (giving points for discussion of medication name, purpose, directions for use, duration of use, and side effects), and patient ratings of physician communication about new prescriptions.
\end{abstract}

RESULTS Twenty-seven physicians prescribed 113 new medications to 82 of 256 patients. The mean $\mathrm{MCl}$ for medications prescribed by physicians in the intervention group was $3.95(S D=1.02)$, significantly higher than that for medications prescribed by control group physicians $(2.86, \mathrm{SD}=1.23, P<.001)$. This effect held regardless of medication type (chronic vs nonchronic medication). Counseling about 3 of the $5 \mathrm{MCl}$ components was significantly higher for medications prescribed by physicians in the intervention group, as were patients' ratings of new medication information transfer $(P=.02)$. Independent of intervention or control groups, higher $\mathrm{MCl}$ scores were associated with better patient ratings about information about new prescriptions $(P=.003)$.

CONCLUSIONS A physician-targeted educational session improved the content of and enhanced patient ratings of physician communication about new medication prescriptions. Further work is required to assess whether improved communication stimulated by the intervention translates into better clinical outcomes.

Ann Fam Med 2013;11:28-36. doi:10.1370/afm.1417.

\section{INTRODUCTION}

$\mathrm{P}$ hysicians prescribing a new medication often fail to discuss basic information about the medication with patients. ' Yet guidelines recommend that physicians educate older adults about such information as the reason for the medication, how to take it, and potential side effects. ${ }^{2,3}$ Furthermore, better patient knowledge about medications is associated with better medication adherence. ${ }^{4}$ Though there is little empirical evidence to guide what physicians in an outpatient setting should discuss when prescribing new medications, studies have shown that patients who reported better and more discussions with their physicians about prescription medications were more adherent to their medications than those who reported receiving less information..$^{5-8}$

Physicians may rely on pharmacists to counsel patients about new prescriptions. ${ }^{9}$ The Omnibus Budget Reconciliation Act of 1990 mandated that pharmacists inform patients about how to use a medication, common or 
severe side effects, potential interactions, and possible contraindications to a medication. ${ }^{10}$ Pharmacists may not know, however, the indication for the medication or how long a patient should take a medication. Furthermore, the amount of information given by pharmacists varies greatly by pharmacy, intensity of state regulations, and the pharmacist's age, ${ }^{11}$ suggesting that physicians may not be able to routinely depend on pharmacists to provide complete information about new prescriptions.

A number of interventions have sought to improve patient education and counseling about medications, ${ }^{12}$ but few have targeted physician communication. ${ }^{13,14}$ Most physician-targeted interventions have focused on improving interactional skills, such as listening skills, patient-centered care, and shared decision making. ${ }^{13-16}$ Those specific to medication-related discussions largely have trained physicians to ask patients to repeat instructions or address their fears about medicines. ${ }^{13}$ Only a few studies emphasized information exchange about medications in the context of actual outpatient office visits. These studies were conducted outside the United States, required several hours of training, and may not be practical for application to busy practicing physicians. ${ }^{17,18}$

This study used a combination of patient surveys and audio recordings of office visits to (1) test the effect of a physician- and patient-targeted intervention to improve communication of basic information about a new medication prescription (assessed using patient ratings of physician communication and analysis of the actual content of audio recorded visits); and (2) evaluate the effect of increased communication about newly prescribed medications (assessed by analyzing the actual content of audio recorded visits) on patient ratings of the information they received about the prescribed medication. We targeted older adults because more than $40 \%$ of older adults are nonadherent to their prescribed medications. ${ }^{19}$

\section{METHODS}

\section{Study Sites and Participants}

The study was conducted from February 2009 to February 2010 in 3 academically affiliated physicians' offices. The investigators recruited physicians from internal medicine and family medicine offices at the University of California, Los Angeles.

Patients of participating physicians were recruited by a part-time research assistant. The assistant telephoned consecutive patients aged 50 years and older 1 to 3 days before their appointment and approached a convenience sample of patients who had not been reached by telephone while they waited in the clinic waiting room. Patients interested in participating were screened for the following inclusion criteria: were English speaking; had a new, worsening, or uncontrolled problem $_{i}$ and agreed to participate in a follow-up visit

\section{Intervention}

The intervention targeted physicians and patients. Approximately one-half of the physicians in each of the 3 participating offices were randomly assigned to the intervention group. A simple randomization was performed using computer-generated random numbers. The physician intervention consisted of a single, 1-hour interactive session (Supplemental Appendix 1, available at http://annfammed.org/content/11/1/28/suppl/ DC1) that emphasized the importance of conveying 5 basic elements of information about new medication prescriptions (medication name, purpose, directions for use, duration of use, and side effects). The session also addressed typical reasons for poor provision of information (eg, fear of scaring patients with side effect information). ${ }^{9}$ Each physician role-played incorporating the 5 basic pieces of information into their normal counseling about a new prescription. Our intervention components were based on educational models used in successful physician-targeted communication interventions that included instruction, modeling, skill practice, feedback, and discussion about communication skills. ${ }^{20,21}$

Patients of physicians in the intervention group were given a 1-page handout to whet their interest in the 5 pieces of information reviewed during the physician education session (Supplemental Appendix 2, available at http://annfammed.org/content/11/1/28/suppl/ DC1). The handout stated that patients receiving a new medication on the day of the visit should make sure they know the name of the medicine, what it is for, how much and how often to take it, how long to take it, and potential side effects. The 5 pieces of information were presented in bullet form. Physicians could write on the handout if they chose, but we did not specifically encourage doing so during the physician educational sessions, and we did not assess whether they did. The research assistant ensured that handouts were given only to patients of intervention group physicians and were not left in waiting rooms or examination rooms.

Intervention group physicians were asked not to share the study aims or educational session content with the control group physicians, who did not receive training. Control group physicians and their patients were told that the study purpose was to investigate best practices for physician-patient communication.

\section{Study Design and Data Collection}

Patients were surveyed immediately before and after an office visit with their physician. The previsit questionnaire could be completed either before or after the 
office visit. All visits were audio-recorded and transcribed verbatim. The study protocol was approved by the Institutional Review Board at the University of California, Los Angeles.

\section{Previsit Survey}

Patients answered questions about their demographics (age, sex, ethnicity, education), the number of prior visits with the physician being seen, and whether the physician was their regular doctor. They also were asked to rate their confidence in interacting with physicians (on a scale from 0 to 10, where higher numbers indicted more confidence). ${ }^{22}$

\section{Postvisit Survey}

Immediately after the visit, patients completed a questionnaire containing previously validated measures of overall physician-patient communication (6 items from the Consumer Assessment of Healthcare Providers and Systems Clinician and Group Survey), ${ }^{23}$ trust in physician (3 items), and health literacy (Rapid Estimate of Adult Literacy in Medicine-Short Form). ${ }^{24}$ Patients also were asked whether they had received a new medication prescription. Those who did were asked whether they were planning to take the medication (yes/no), and to rate their certainty about taking the new medication ("On a scale from 0 to $10 \ldots$ how sure are you that you will be able to take your new medication exactly as prescribed over the next 30 days?"). Patients who were prescribed a new medication also rated the importance of the new medication and their worry about the condition for which the medication was prescribed (4-point Likert scale). Patients' perception of communication about the new medication was assessed by summing their ratings of information received about 10 new medication-related topics (Cronbach's $\alpha=.84$ ). Responses were dichotomized $(1=$ about right, $0=$ too much, too little, or none received), averaged, and transformed into a scale ranging from 0 to 10 .

\section{Qualitative Analysis}

We analyzed transcripts of visits in which patients reported receiving a new medication prescription. We defined a new medication prescription as one that the patient had never taken and was in a medication class that differed from previously prescribed medications. If a patient had been previously prescribed a medications, but never started taking it, the prescription was not included in our analysis. Analysis was performed at the medication level.

Three authors used previously established codes and coding rules for medication prescriptions to code for statements about medication name, purpose of use, number of tablets or sprays, dosing frequency, duration of use, and side effects and adverse reactions. ${ }^{1,25}$ They also coded for whether statements were physician- or patient-initiated. Coders had diverse backgrounds-a family physician experienced in qualitative research methods (D.M.T.), a medical sociologist (D.A.P.), and a premedical student research assistant with no qualitative research experience (D.K.O.). Coders were blinded to whether visits were to physicians in the intervention or control group. The name of the medication was coded only if the actual name (either generic or brand name) was mentioned. We did not code references such as "an antibiotic" or "a blood pressure medication" as satisfactory statements of a medication's name. The lead author (D.M.T.) coded all of the transcripts. Other investigators independently coded $28 \%$ (D.A.P.) and 31\% (D.K.O.) of randomly selected transcripts; they achieved mean Cohen's $\mathrm{\kappa}$ for interrater reliabilities of $0.91(\mathrm{SD}=0.13$, range $=0.65-1.0)$ and $0.90(\mathrm{SD}=0.09$, range $=0.79-1.0)$, respectively. Discrepancies between coders were resolved by consensus or group discussions among all authors.

\section{Medication Communication Index}

The Medication Communication Index (MCI) was calculated for each newly prescribed medication based on qualitative analysis of the transcripts. It is a previously developed 5 -point index in which 1 point is given for discussion about each of 5 topics related to a new prescription: medication name, purpose of use, directions for use (comprised of 0.5 points for number of tablets or sprays, and 0.5 points for dosing frequency), duration of use, and side effects and adverse reactions. ${ }^{1}$

\section{Statistical Analyses}

Stata 11.0 (StataCorp LP) was used for all statistical analyses. Because patients were clustered within physicians, we used generalized estimating equations (GEE) method to assess the relationship of the intervention on the MCI, overall, by physician characteristics (practicing vs resident physician), and by medication type (chronic vs nonchronic medication). The GEE method adjusted for physician effects to control for the possible correlation of patient outcomes within the same physician. Similarly, we used the GEE method to examine the effect of the intervention on the individual MCI components. Bivariate analyses were conducted, using the GEE method to examine the relationship of (1) the intervention, and (2) the MCI, with patient reports about the physician and the new medication prescription.

\section{RESULTS}

Of 1,117 patients who were approached in waiting rooms or telephoned, 917 were reached. Of these, 222 


\section{Figure 1. Flowchart of study participants.}

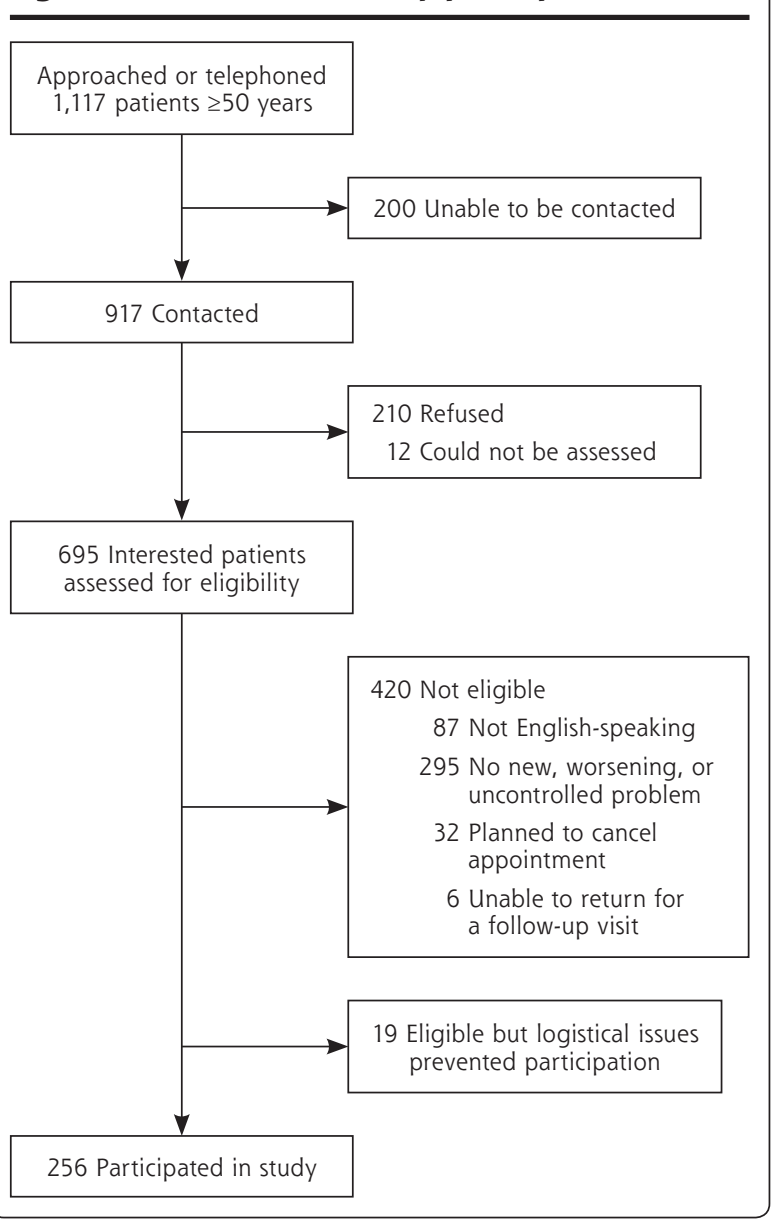

refused or could not be assessed, and 420 patients were ineligible (295 had no new, worsening, or uncontrolled problem; 87 did not speak English; 32 planned to cancel their appointment; and 6 were unable to follow-up). Two hundred fifty-six patients were enrolled (Figure 1). The eligibility rate among those screened for study participation was $39.6 \%$ (eligible patients/total patients for whom eligibility was determined $=(256+19) /(256+420+19)$, and the response rate among all potential eligible patients was $57.9 \%$ (ie, 256/[256+19+( $0.396 \times[210+12+200])])$, which is consistent with other studies using similar methodologies. ${ }^{26}$

Twenty-seven of 29 physicians approached participated. Physicians consisted of 13 practicing physicians (7 general internists and 6 family physicians) and 14 internal medicine residents. Approximately one-half of the physicians (7 practicing physicians and 8 resident physicians) were randomly assigned to the intervention group.
Of the 27 participating physicians, 18 prescribed 113 new medications to 82 patients. We were unable to capture new medication prescriptions for 9 of 14 physicians in training because of their limited office schedules and small number of office visits with older patients. Among physicians for whom we captured at least 1 new medication prescription, most were white $(61 \%)$ and male (61\%) (Table 1). There were no significant differences between intervention and control group physician characteristics. Patients were mostly white $(61.7 \%)$, had a mean age of 64.8 years $(\mathrm{SD}=10.5$ years), and had at least some college education $(82.3 \%$ ) (Table 2).

Most common among newly prescribed medications were analgesics (13.3\%) and cough and cold preparations (10.6\%). Dermatologic preparations, decongestants and nasal sprays, gastrointestinal medications, and antibiotics each comprised slightly more than $8 \%$ of new medications; antihypertensive medications, inhalers, and antidepressants or mood stabilizers each comprised $6.2 \%$, and lipid-lowering medications comprised $3.5 \%$ of newly prescribed medications.

\section{Effect of the Intervention}

The mean MCI for medications prescribed by physicians in the intervention group was 3.95 (SD =1.02), significantly higher than the MCI for medications prescribed by control group physicians $(2.86, \mathrm{SD}=1.23$, $P<.001)$. This effect held for attending and resident physicians and for medications prescribed for chronic and nonchronic conditions (Figure 2). Each of the MCI components (name, purpose, number of tablets or sprays, dosing frequency, duration of use, side effects) was discussed more frequently for medications prescribed by intervention group physicians. These differences were significant for all but medication purpose and side effects. Compared with the control group physicians, intervention group physicians provided information about the medication name, number of tablets, dosing frequency, duration of use, and side effects for at least $20 \%$ more of their newly prescribed

\begin{tabular}{|lccc|}
\hline Table 1. Characteristics of Physicians & & \\
\hline & $\begin{array}{c}\text { Prescribing a } \\
\text { New Medication }\end{array}$ & $\begin{array}{c}\text { Intervention } \\
\text { Group }\end{array}$ & $\begin{array}{c}\text { Control } \\
\text { Group }\end{array}$ \\
Characteristic & $\mathbf{( N = 1 8 )}$ & $\mathbf{( n = 1 0 )}$ & (n= 8) \\
\hline Age, mean (SD), y & $38.8(11.3)$ & $41.6(13.7)$ & $35.3(6.5)$ \\
Female, No. (\%) & $7(39)$ & $4(40)$ & $3(38)$ \\
Race/ethnicity, No. (\%) & $11(61)$ & $6(60)$ & $5(63)$ \\
White & $7(39)$ & $4(40)$ & $3(38)$ \\
Asian & $13.7(11.8)$ & $16.4(14.3)$ & $10.3(7.3)$ \\
Years in practice, mean (SD) & & & \\
\hline Note: No difference between intervention and control group physicians was statistically significant.
\end{tabular}




\section{Table 2. Characteristics of Patients}

\begin{tabular}{|c|c|c|c|c|c|}
\hline \multirow[b]{2}{*}{ Characteristic } & \multirow[b]{2}{*}{$\begin{array}{l}\text { All Patients } \\
(\mathrm{N}=256)\end{array}$} & \multirow{2}{*}{$\begin{array}{l}\text { Prescribed } \\
\text { a New } \\
\text { Medication } \\
(\mathrm{n}=82)\end{array}$} & \multirow{2}{*}{$\begin{array}{c}\text { Not Prescribed } \\
\text { a New } \\
\text { Medication } \\
(n=174)\end{array}$} & \multicolumn{2}{|c|}{ Prescribed a New Medication } \\
\hline & & & & $\begin{array}{c}\text { Intervention } \\
\text { Group } \\
(n=46)\end{array}$ & $\begin{array}{l}\text { Control } \\
\text { Group } \\
(n=36)\end{array}$ \\
\hline Age, mean (SD), y & $64.8(10.5)$ & $60.5(8.0)$ & $66.8(11.0)$ & $60.3(7.9)$ & $60.7(8.3)$ \\
\hline Female, No. (\%) & $150(58.6)$ & $50(61.0)$ & $100(57.5)$ & $30(65.2)$ & $20(55.6)$ \\
\hline \multicolumn{6}{|l|}{ Race/ethnicity, No. (\%) } \\
\hline White & $158(61.7)$ & $49(59.8)$ & $109(62.6)$ & $26(56.5)$ & $23(63.9)$ \\
\hline African-American & $43(16.8)$ & $15(18.3)$ & $28(16.1)$ & $7(15.2)$ & $8(22.2)$ \\
\hline Hispanic & $24(9.4)$ & $12(14.6)$ & $12(6.9)$ & $9(19.6)$ & $3(8.3)$ \\
\hline Asian & $21(8.2)$ & $5(6.1)$ & $16(9.2)$ & $3(6.5)$ & $2(5.6)$ \\
\hline Other & $8(3.1)$ & $1(1.2)$ & $7(4.0)$ & $1(2.2)$ & $0(0)$ \\
\hline \multicolumn{6}{|l|}{ Education, No. (\%) } \\
\hline High school or less & $45(17.7)$ & $15(18.5)$ & $30(17.4)$ & $10(22.2)$ & $5(13.9)$ \\
\hline Some college & $85(33.3)$ & $28(34.8)$ & $57(32.8)$ & $15(33.3)$ & $13(36.1)$ \\
\hline College graduate & $125(49.0)$ & $38(46.9)$ & $87(50.0)$ & $20(44.4)$ & $18(50.0)$ \\
\hline Health literacy score, mean (SD) ${ }^{a}$ & $6.7(0.89)$ & $6.8(0.49)$ & $6.7(1.0)$ & $6.8(0.53)$ & $6.9(0.44)$ \\
\hline $\begin{array}{l}\text { Medications and dietary supplements, mean } \\
\text { (SD), No. }\end{array}$ & $6.8(4.4)$ & $6.7(3.9)$ & $6.8(4.6)$ & $6.7(3.6)$ & $6.6(4.2)$ \\
\hline $\begin{array}{l}\text { Confidence about interacting with physicians, } \\
\text { mean score }(S D)^{b}\end{array}$ & $8.6(1.5)$ & $8.6(1.5)$ & $8.6(1.6)$ & $8.9(1.1)$ & $8.3(1.9)$ \\
\hline Seen by internal medicine physician, No. (\%) & $158(61.7)$ & $55(67.1)$ & $103(59.2)$ & $30(65.2)$ & $25(69.4)$ \\
\hline Seen by attending physician, No. (\%) & $225(87.9)$ & $71(86.6)$ & $154(88.5)$ & $40(87.0)$ & $31(86.1)$ \\
\hline Seen by patient's regular physician, No. (\%) & $214(86.0)$ & $64(82.1)$ & $150(87.7)$ & $36(83.7)$ & $28(80.0)$ \\
\hline \multicolumn{6}{|l|}{ Previous visits to physician, No. (\%) } \\
\hline Never & $36(14.8)$ & $15(19.2)$ & $21(12.7)$ & $5(11.9)$ & $10(27.8)$ \\
\hline $1-2$ & $35(14.4)$ & $11(14.1)$ & $24(14.6)$ & $7(16.7)$ & $4(11.1)$ \\
\hline $3-5$ & 49 (20.2) & $13(16.7)$ & $36(21.8)$ & $7(16.7)$ & $6(16.7)$ \\
\hline $6-12$ & 48 (19.7) & $14(18.0)$ & 34 (20.6) & $8(19.1)$ & $6(16.7)$ \\
\hline$>12$ & 75 (30.9) & $25(32.1)$ & $50(30.3)$ & $15(35.7)$ & $10(27.8)$ \\
\hline
\end{tabular}

\section{Figure 2. Medical Communication Index scores for medications prescribed by intervention and control group physicians.}

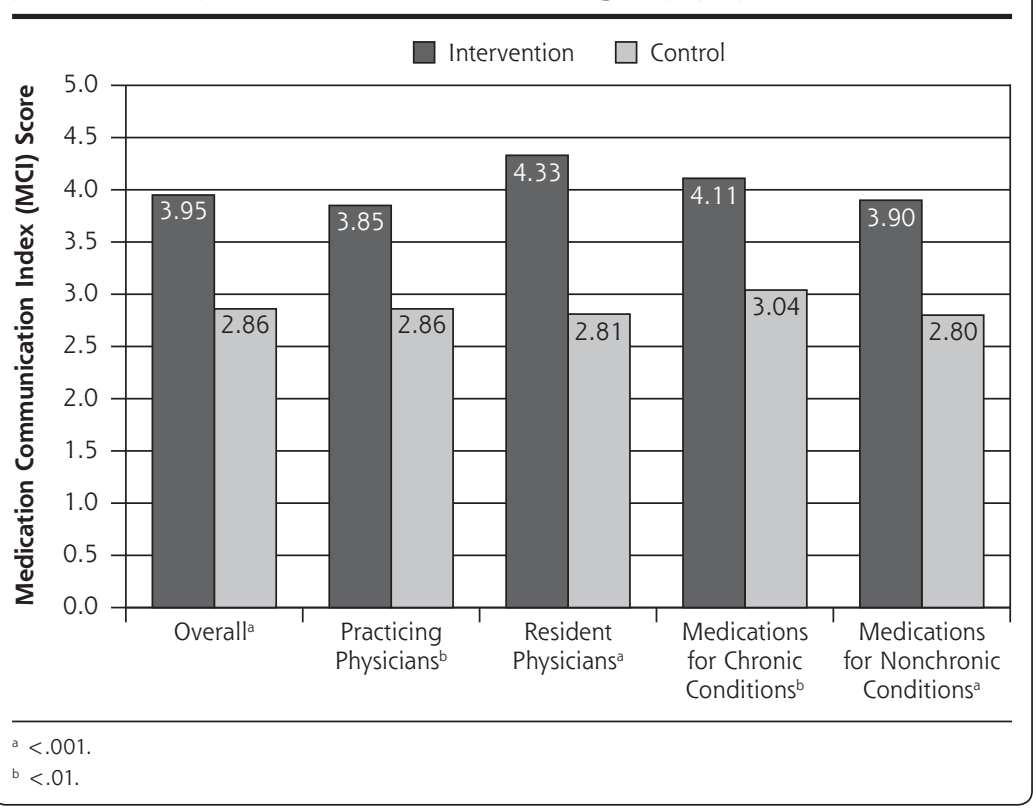

medications (Figure 3). Patients initiated few discussions about the $\mathrm{MCI}$ components: $1.8 \%$ of discussions were about medication purpose $3.6 \%$ of discussions were about medication name, number of tablets or sprays, dosing frequency and duration of use, and $5.5 \%$ of discussions were about side effects.

Table 3 illustrates the effect of the intervention on patients' reports about physician communication and new medication prescriptions. There were no significant differences between intervention and control group patients in reported overall physician communication or trust in the physician. On a scale from 0 to 10 (with higher scores indicating better communication), however, patients reported significantly better communication about medications 


\section{Figure 3. Percentage of medications for which Medication Communication Index component was discussed.}

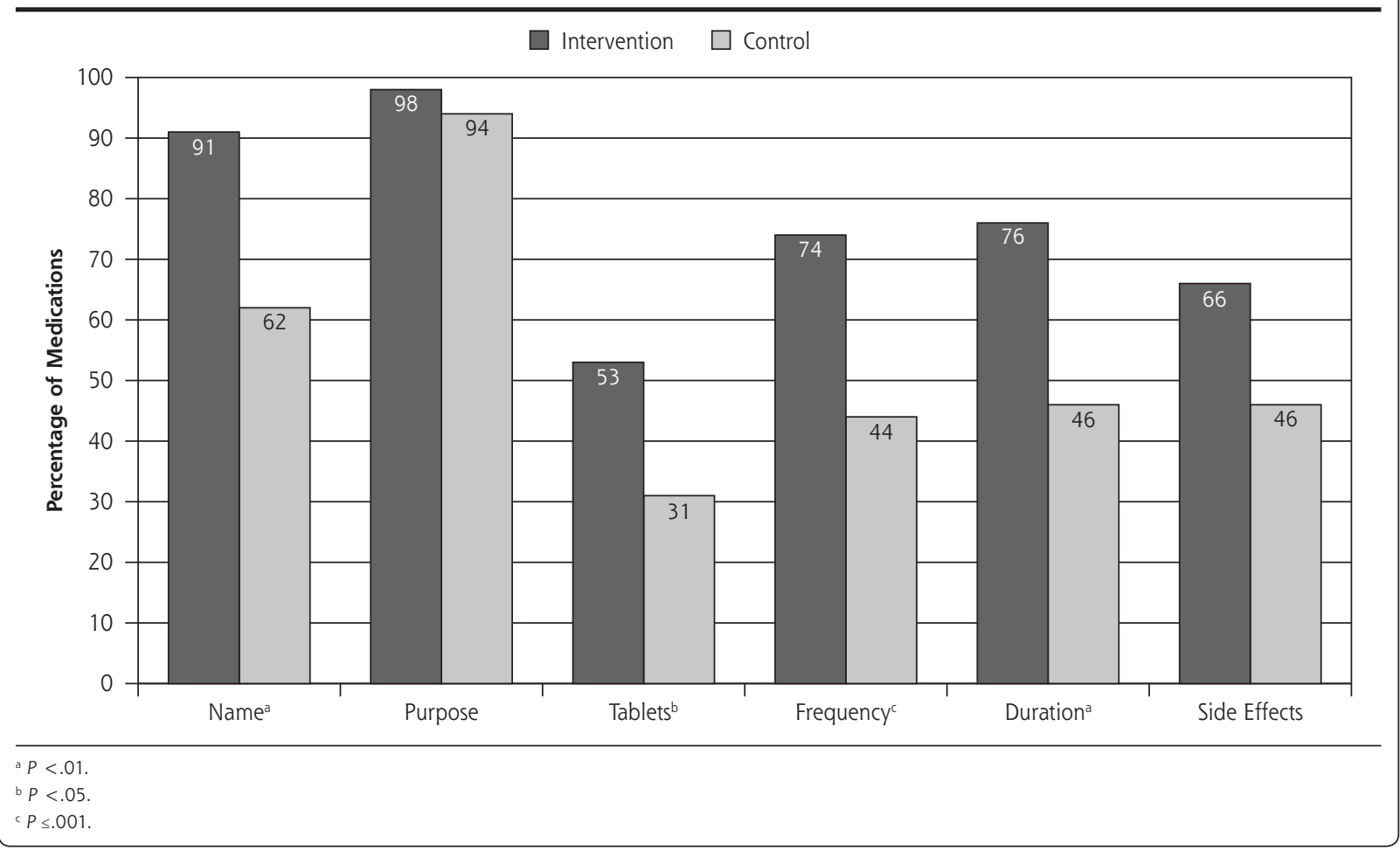

Table 3. Effect of Intervention on Patients' Reports About Physician Communication and Medication

\begin{tabular}{|c|c|c|c|c|c|}
\hline Report & $\begin{array}{l}\text { No. of } \\
\text { Patients }\end{array}$ & All Patients & $\begin{array}{c}\text { Intervention } \\
\text { Group }\end{array}$ & $\begin{array}{l}\text { Control } \\
\text { Group }\end{array}$ & $P$ Value \\
\hline \multicolumn{6}{|l|}{ About physician } \\
\hline Overall communication, mean score (SD) & 82 & $5.67(0.60)$ & $5.74(0.54)$ & $5.59(0.66)$ & .49 \\
\hline Trust in physician, mean score (SD) & 82 & $4.68(0.55)$ & $4.72(0.52)$ & $4.62(0.59)$ & .68 \\
\hline Communication about new medication, No. $(\%)^{b}$ & 111 & $7.90(2.81)$ & $8.78(2.23)$ & 6.87 (3.09) & .02 \\
\hline What medicine is called & 107 & $103(96.3)$ & $56(94.9)$ & $47(97.9)$ & .53 \\
\hline What medicine is for & 106 & $105(99.1)$ & $57(98.3)$ & $48(100)$ & .36 \\
\hline Why medicine is important to take & 103 & $90(87.4)$ & $51(89.5)$ & $39(84.8)$ & .63 \\
\hline How to take the medicine & 102 & $95(93.1)$ & $54(96.4)$ & $41(89.1)$ & .07 \\
\hline How long to take medicine & 103 & $92(89.3)$ & $56(96.6)$ & $36(80.0)$ & .03 \\
\hline How to get further medicine supply (if applicable) & 81 & $69(85.2)$ & $42(82.4)$ & $30(90.9)$ & .37 \\
\hline Whether medicine has side effects & 103 & $75(72.8)$ & $50(86.2)$ & $25(55.6)$ & .001 \\
\hline Risk of getting side effects & 105 & $64(61.0)$ & $43(76.8)$ & $21(42.9)$ & .003 \\
\hline What to do if side effects occur & 100 & $63(63.0)$ & $40(74.1)$ & $23(50.0)$ & .008 \\
\hline Interactions with other medicines & 100 & $62(62.0)$ & $43(81.1)$ & $19(40.4)$ & $<.001$ \\
\hline \multicolumn{6}{|l|}{ About new medication immediately after the visit } \\
\hline Planning to take new medication, No. (\%) & 110 & $107(97.3)$ & $59(98.3)$ & $48(96.0)$ & .56 \\
\hline Certainty about taking new medication, mean score (SD) & 111 & $8.94(2.16)$ & $9.30(1.96)$ & $8.51(2.29)$ & .04 \\
\hline Importance of new medication, mean score (SD) & 111 & $3.61(0.62)$ & $3.65(0.61)$ & $3.57(0.64)$ & .52 \\
\hline Worry about condition medication is for, mean score (SD) & 111 & $2.36(1.02)$ & $2.45(1.08)$ & $2.25(0.93)$ & .32 \\
\hline \multicolumn{6}{|c|}{$\begin{array}{l}\text { Note: Data are presented as mean (SD) unless otherwise indicated. Unit of analyses for overall communication and trust in physician is the patient; unit of analyses fo } \\
\text { all other outcomes is the new medication. Overall communication ranges from } 1 \text { to } 6 \text {; trust in physician ranges from } 1 \text { to } 5 \text {; communication about new medication an } \\
\text { certainty about taking new medication range from } 0 \text { to } 10 \text {; and importance of new medication and worry about condition range from } 1 \text { to } 4 \text {. Higher scores indicate } \\
\text { better communication, more trust, and greater certainty, importance, and worry. }\end{array}$} \\
\hline \multicolumn{6}{|c|}{ a $P$ value describes difference between intervention and control group patients. } \\
\hline \multicolumn{6}{|c|}{$\begin{array}{l}\text { b The } 10 \text { items comprising the communication about new medication scale are listed and describe the number and percentage of patients who reported receiving } \\
\text { "about the right amount" of information about the item. }\end{array}$} \\
\hline
\end{tabular}


prescribed by intervention group physicians $(8.78, \mathrm{SD}=2.23)$ than those prescribed by control group physicians $(6.87$, $\mathrm{SD}=3.09)(P=.02)$. These differences were driven largely by differences in communication about how long to take the medication $(P=.03)$, whether the medicine has side effects $(P=.001)$, the risk of having side effects $(P=.003)$, what to do if side effects occur $(P=.008)$, and potential interactions with other medications $(P$ $<.001)$. Immediately after the visit, intervention group patients generally had reports about new medications that were more positive than those of control group patients, though the only report that was statistically significant was certainty about taking new medications over the next 30 days $(P=.04)$.

\section{Effect of Increased Communication About New Prescriptions (Medication Communication Index)}

Table 4 relates $\mathrm{MCI}$ scores to patients' reports of physicians and new medication prescriptions. Higher MCI scores (indicating discussion of more $\mathrm{MCI}$ components) were significantly related to better patients' reports of communication about new medications $(P=.003)$. This difference was largely because higher MCI scores resulted in significantly better patients' reports of what the medicine was for $(P<.001)$, how long to take a medication $(P=.03)$, whether the medicine has side effects $(P=.02)$, the risks of having side effects $(P<.001)$, and what to do if side effects occur $(P<.001)$.

\section{DISCUSSION}

A simple intervention combining physician education and role playing with a patient information handout can improve communication about basic medicationrelated elements (name, purpose, directions for use, duration of use, side effects) when a new medication is prescribed. On average, intervention group physicians addressed more than 1 of 5 additional elements of basic information compared with control group physicians; they also had more discussions than control group physicians about all 5 major elements emphasized by the intervention. Furthermore, the intervention resulted in patients reporting better communication about medication information.

Previous studies have shown that patient educational interventions can improve medication adherence and patient health outcomes. ${ }^{27,28}$ Though a recent literature review suggested that there is insufficient evidence to support patient educational interventions alone for improving patient knowledge about and adherence to health treatments, ${ }^{12}$ the interventions reviewed were not medication specific and used a mixture of written and verbal counseling strategies. Though physician communication is only one among many factors influencing patient medication adher- 
ence, ${ }^{4}$ the physician-patient interaction often serves as a patient's introduction to a medication, may affect whether the patient decides to fill a medication, and creates the context in which a new medication is experienced, including anticipation of therapeutic effects and interpretation of side effects. More than 25\% of patients never fill new prescriptions for chronic conditions, such as hypertension, hyperlipidemia, and diabetes, ${ }^{29}$ and $20 \%$ to $50 \%$ discontinue these medications within 6 months of starting them. ${ }^{30}$ Measures to enhance adherence (eg, reminder telephone calls and pharmacist interventions ${ }^{12}$ ) are not salient if the original prescription is never filled. This study did not evaluate whether better communication affected medication adherence; this relationship should be explored.

This study shows that the MCI captures elements of medication communication that are transmitted to and then recalled by patients. Patients reported receiving better communication about a new medication when physicians conveyed more MCI elements about a new medication. Interestingly, higher MCI scores also were associated with more reports of communication about topics not directly included in the intervention. For example, the intervention encouraged physicians to discuss potential medication side effects with patients, but patients also reported better communication about the risk of experiencing side effects and what to do if side effects occurred. We did not code transcripts for these elements of discussion. This finding, however, suggests that new medication discussions which include more basic elements of medication communication are also more complete in other ways.

Our study has several limitations. First, the patients were a convenience sample, and data were not collected to evaluate differences between study participants and those who declined to participate. Patients in the study were predominantly white, most had at least some college education, and few were of lower health literacy. Intervention group patients were comprised of a larger percentage of Hispanics and a lower percentage of African-Americans. Further investigation is needed to examine how these imbalances may have affected our results regarding communication about new medication prescriptions. Second, having an audio recorder in the examination room may introduce the Hawthorne effect, and thus may have enhanced medication communication for physicians in the intervention group compared with those physicians in the control group. Third, the study did not examine interactional components of communication, such as style of communication. It also did not assess the quality of the information transmitted, and the intervention did not target these elements. Fourth, we had a long recruitment period because most of the academic physicians in our study did not see patients full-time (some only a half-day per week), and research assistants were available only part-time. In addition, some of the physicians, particularly the physicians in training, saw few patients aged 50 years and older. These factors prolonged recruitment and potentially increased opportunities for contamination between the invention and control groups, although this would have minimized the intervention effect. Lastly, we did not examine whether the intervention increased the time spent communicating about new prescriptions, or whether any additional time spent discussing new prescriptions lengthened visits or adversely affected counseling about other aspects of care.

When physicians introduce a new medication, the stage is set for whether and how patients will initiate use of this medication. In 2008, the Institute of Medicine called for more research to support physician counseling at the time of prescribing. ${ }^{31}$ This study shows that a brief, practical intervention can improve physician communication about a newly prescribed medication in ways that affect patients. The intervention should be tested for its clinical impact.

To read or post commentaries in response to this article, see it online at http://www.annfammed.org/content/11/1/28.

Key words: physician-patient relations; prescriptions; communication; intervention studies

Submitted November 28, 2011; submitted, revised, March 25, 2012; accepted April 10, 2012.

Funding support: Dr Tarn was supported by a UCLA Mentored Clinical Scientist Development Award (5K12AG001004) and by the UCLA Claude D. Pepper Older Americans Independence Center, funded by the National Institute of Aging (5P30 AG028748).

Disclaimer: The article content does not necessarily represent the official views of the National Institute on Aging or the National Institutes of Health. The investigators retained full independence in the conduct of this study.

Previous presentation: This study was presented at the North American Primary Care Research Group meeting in Banff, Alberta, Canada, on November 13, 2011.

Acknowledgments: The authors would like to thank the physicians and patients from the UCLA Internal Medicine and Family Medicine practices who participated in the study. They also wish to acknowledge Jeffrey Good, PhD, for his assistance with data management and for his feedback on the manuscript.

\section{References}

1. Tarn DM, Heritage J, Paterniti DA, Hays RD, Kravitz RL, Wenger NS. Physician communication when prescribing new medications. Arch Intern Med. 2006;166(17):1855-1862.

2. Shrank WH, Polinski JM, Avorn J. Quality indicators for medication use in vulnerable elders. J Am Geriatr Soc. 2007;55(Suppl 2): S373-S382. 
3. Knight EL, Avorn J. Quality indicators for appropriate medication use in vulnerable elders. Ann Intern Med. 2001;135(8 Pt 2):703-710.

4. Murray MD, Morrow DG, Weiner M, et al. A conceptual framework to study medication adherence in older adults. Am J Geriatr Pharmacother. 2004;2(1):36-43.

5. Falvo D, Woehlke P, Deichmann J. Relationship of physician behavior to patient compliance. Patient Couns Health Educ. 1980;2(4):185-188.

6. Hulka BS, Cassel JC, Kupper LL, Burdette JA. Communication, compliance, and concordance between physicians and patients with prescribed medications. Am J Public Health. 1976;66(9):847-853.

7. Bull SA, Hu XH, Hunkeler EM, et al. Discontinuation of use and switching of antidepressants: influence of patient-physician communication. JAMA. 2002;288(11):1403-1409.

8. Svarstad BL. The Doctor-Patient Encounter: An Observational Study of Communication and Outcome. [Doctoral dissertation]. University of Wisconsin; 1974:1-338.

9. McGrath JM. Physicians' perspectives on communicating prescription drug information. Qual Health Res. 1999;9(6):731-745.

10. Omnibus Budget Reconciliation Act of 1990 Public Law 101-508, S 4401, November 5, 1990.

11. Svarstad BL, Bultman DC, Mount JK. Patient counseling provided in community pharmacies: effects of state regulation, pharmacist age, and busyness. J Am Pharm Assoc (2003). 2004;44(1):22-29.

12. Ryan R, Santesso N, Hill S, Lowe D, Kaufman C, Grimshaw J. Consumer-oriented interventions for evidence-based prescribing and medicines use: an overview of systematic reviews. Cochrane Database Syst Rev. 2011;5(5):CD007768.

13. Stevenson FA, Cox K, Britten N, Dundar Y. A systematic review of the research on communication between patients and health care professionals about medicines: the consequences for concordance. Health Expect. 2004;7(3):235-245.

14. Griffin SJ, Kinmonth AL, Veltman MW, Gillard S, Grant J, Stewart $M$. Effect on health-related outcomes of interventions to alter the interaction between patients and practitioners: a systematic review of trials. Ann Fam Med. 2004;2(6):595-608.

15. Lewin SA, Skea ZC, Entwistle V, Zwarenstein M, Dick J. Interventions for providers to promote a patient-centred approach in clinical consultations. Cochrane Database Syst Rev. 2001;(4):CD003267.

16. Légaré $F$, Ratté $S$, Stacey $D$, et al. Interventions for improving the adoption of shared decision making by healthcare professionals. Cochrane Database Syst Rev. 2010;(5):CD006732.

17. Lacroix A, Courvoisier F, Aufseesser-Stein M, Assal JP. Le dialogue de prescription. Lacunes et possibilité d'amélioration par un bref enseignement interactif. (in French). [The dialogue of prescribing. Gaps and possibilities for improvement with a brief interactive seminar]. Schweiz Rundsch Med Prax. 1992;81(6):138-141.

18. Aufseesser-Stein M, Rüttimann S, Lacroix A, Assal JP. Expérience suisse de formation au dialogue de prescription en médecine ambulatoire. (in French). [Swiss educational experience with a prescription dialogue in ambulatory medicine]. Schweiz Rundsch Med Prax. 1992;81(6):142-146
19. Safran DG, Neuman $P$, Schoen $C$, et al. Prescription drug coverage and seniors: findings from a 2003 national survey. Health Aff (Millwood). 2005;(Suppl Web Exclusives):W5-152-W5-166.

20. Hulsman RL, Ros WJ, Winnubst JA, Bensing JM. Teaching clinically experienced physicians communication skills. A review of evaluation studies. Med Educ. 1999;33(9):655-668.

21. Rao JK, Anderson LA, Inui TS, Frankel RM. Communication interventions make a difference in conversations between physicians and patients: a systematic review of the evidence. Med Care. 2007; 45(4):340-349.

22. Maly RC, Frank JC, Marshall GN, DiMatteo MR, Reuben DB. Perceived efficacy in patient-physician interactions (PEPPI): validation of an instrument in older persons. J Am Geriatr Soc. 1998;46(7): 889-894.

23. Reporting Measures for the CAHPS Clinician \& Group Survey. From the CAHPS Clinician \& Group Survey and Reporting Kit. Rockville, MD: Agency for Healthcare Research and Quality; 2007. https://www .cahps.ahrq.gov/cahpskit/files/309_CEG_Reporting_Measures.htm.

24. Davis TC, Long SW, Jackson RH, et al. Rapid estimate of adult literacy in medicine: a shortened screening instrument. Fam Med. 1993;25(6):391-395.

25. Tarn DM, Heritage J, Paterniti DA, Hays RD, Kravitz RL, Wenger NS. Prescribing new medications: a taxonomy of physician-patient communication. Commun Med. 2008;5(2):195-208.

26. Themessl-Huber M, Humphris G, Dowell J, Macgillivray S, Rushmer R, Williams B. Audio-visual recording of patient-GP consultations for research purposes: a literature review on recruiting rates and strategies. Patient Educ Couns. 2008;71(2):157-168.

27. Roter DL, Hall JA, Merisca R, Nordstrom B, Cretin D, Svarstad B. Effectiveness of interventions to improve patient compliance: a meta-analysis. Med Care. 1998;36(8):1138-1161.

28. Peterson AM, Takiya L, Finley R. Meta-analysis of trials of interventions to improve medication adherence. Am J Health Syst Pharm. 2003;60(7):657-665.

29. Fischer MA, Stedman MR, Lii J, et al. Primary medication nonadherence: analysis of 195,930 electronic prescriptions. J Gen Intern Med. 2010;25(4):284-290.

30. Osterberg L, Blaschke T. Adherence to medication. $N$ Engl J Med. 2005;353(5):487-497.

31. Hernandez LM. Institute of Medicine Roundtable on Health Literacy. Institute of Medicine Board on Population Health and Public Health Practice. Standardizing Medication Labels: Confusing Patients Less: Workshop Summary. Washington, DC: National Academies Press; 2008. 